\title{
Serum Metabonomic Study of 2 Uyghur Probable MODY Families Based on ${ }^{1} \mathrm{H}$ NMR
}

\author{
Aierken Taxitiemuer ${ }^{2}$, Yilihamujiang Yimamu ${ }^{1 *}$, Patamu Mohemaiti ${ }^{1 *}$ and Rebiya Nuli ${ }^{1}$ \\ ${ }^{1}$ Xinjiang Medical University, Urumqi, Xinjiang, China \\ ${ }^{2}$ Centre of disease control and prevention of Xinjiang, Urumqi, Xinjiang, China
}

\begin{abstract}
Objective: To study the characteristics of changes in serum metabolites in two Uyghur families with probable maturity-onset diabetes of young (MODY).

Method: We gathered two probable MODY families composed of four generations of Uyghurs from Kashgar region, Xinjiang Uyghur Autonomous Region, China. A total of 52 family members were gathered. Their general information, measured blood glucose levels, blood lipid levels, and blood pressure were analyzed. Using ${ }^{1} \mathrm{H}$ Nuclear Magnetic Resonance ( ${ }^{1} \mathrm{H}$ NMR) spectroscopy, serum metabolites were measured for each study participants. After having conducted data pretreatment on the spectrogram, orthogonal partial least squares discriminant analysis (OPLS-DA) was used to interpret data. We divided subjects into two groups according to blood glucose (normal and high), blood presure, body mass index (BMI) levels, and compared the metabolites. We determined differences of metabolism components between each group's serum using pearson correlation coefficients with significant difference detection and two-dimensional spectrum technology.
\end{abstract}

Results: (1)Isoleucine and tyrosine levels were decreased significantly $(p<0.05)$ and $\alpha$-glucose, $\beta$-glucose levels were increased obviously $(p<0.05)$, when high blood glucose group compared with normal blood glucose group (2) Citrate, phaseomannite, 1 -methyl histidine and tyrosine levels were all decreased significantly $(p<0.05)$, when comparing serum metabolites between hypertension group and normal blood presure group in probable MODY family members (3) No significant metabonomic changes were observed when comparing normal BMI group and high BMI group.

Conclusion: The metabolites in the serum of Uyghur probable MODY family members were very different in different groups. Isoleucine, citrate, inositol, 1-methylhistidine and tyrosine are the differential metabolites, these metabolites can be considered as candidate biomarkers for predicting probable MODY. Differences of the metabolites in serum of probable MODY families suggested that the TCA cycle metabolic disorder and the obstruction of fat metabolism in the patients of the probable MODY families.

Keywords: Probable MODY family; Metabonomic study; ${ }^{1} \mathrm{H}$ NMR

\section{Introduction}

The prevalence of diabetes is growing dramatically, and more and more young people are being affected. That is why the early diagnosis is especially important, which in turn makes metabolites group study of diabetes indispensable. In 1984, Nicholson et al found that the density level in some metabolites in the urine of a diabetic patient and in the sample of a normal person is quite different [1]. Mäkinen et al applied ${ }^{1} \mathrm{H}$ NMR technology to identify the characteristics of diabetic and normal metabolites [2]. Jin et al analyzed the blood ${ }^{1} \mathrm{H}$ NMR spectrum and ${ }^{13} \mathrm{C}$ NMR spectrum of Zucker diabetic obese mice, and discovered the metabolic pathways of glucose in sick state [3].

MODY is an autosomal dominant single gene hereditary disease. Clinically it has heterogenetic, and non-ketone sickness tendency, and usually appears before the age of 25 with three generations or above of family illness history. It mostly occurs in children and adolescents, characterized by $\beta$ cell disfunction and account for about $2 \%-5 \%$ of type 2 diabetes [4]. Researches on MODY family pedigree are rarely reported. This study was based on two Uyghur probable MODY families from Xinjiang's Kashgar region and the serum samples of their 52 members were analyzed with the use of ${ }^{1} \mathrm{H}$ NMR technology to measure metabolites and explore the metabolic characteristics of probable MODY families. Through comparative analysis of metabolites, we want to speculate the mechanism or characteristics of persons with probable MODY and to seek for suspected probable MODY biologically designated objects.

\section{Materials and Methods}

\section{Subject of the study}

Two probable MODY families composed of 52 members from four generations of people in Xinjiang's Kashgar region were included with their informed consents in this study (family tree is showed in Figure 1, Figure 2). The mean age and standard deviation of the family members was $32.39 \pm 19.13$ years with 26 males (mean age $34.88 \pm 20.67$ years) and 26 females (mean age $30.00 \pm 17.61$ years).

MODY families were suspected according to 14 years of follow-up and the clinical features which satisfied the following criteria: (1)Age of disease onset was less than 25 years old; (2)At least two patients in one family, at least three generations of MODY patients with autosomal dominance; (3)Administration of oral hypoglycemic therapy for at

*Corresponding authors: Patamu Mohemaiti, Public Health College, Xinjiang Medical University, Urumqi, Xinjiang, China, Tel: 08613565988794; E-mail: patam0616@yahoo.com.cn

Yilihamujiang Yimamu, Endocrinology Department of the first affiliated hospital of Xinjiang Medical University, China, E-mail: ilhamprof@hotmail.com

Received January 18, 2011; Accepted April 09, 2011; Published April 15, 2011

Citation: Taxitiemuer A, Yimamu Y, Mohemaiti P, Nuli R (2011) Serum Metabonomic Study of 2 Uyghur Probable MODY Families Based on ${ }^{1} \mathrm{H}$ NMR. J Diabetes Metab 2:122. doi:10.4172/2155-6156.1000122

Copyright: (c) 2011 Taxitiemuer A, et al. This is an open-access article distributed under the terms of the Creative Commons Attribution License, which permits unrestricted use, distribution, and reproduction in any medium, provided the original author and source are credited. 
least 5 years or the effective blood plasma $\mathrm{C}$ peptide level was normal. (4)Insulin levels often in the normal range, though inappropriately low for the degree of hyperglycemia, suggesting a primary defect in betacell function. (5)Normal body habitus, with generally low incidence of overweight or obesity [5]. Genetic study was also done.All exons and flanking intron regions of HNF- $4 \alpha$, GCK, HNF-1 $\alpha$, IPF- 1 , HNF-1 $\beta$, and NEUROD1 genes were amplified and sequenced. HNF-1 $\alpha$ exon7 p.Gln497Gln and NEUROD1 Exon1 c.164G>A was novel variations. Others were previously described common polymorphisms [6].

Grouping criteria: Subjects were divided into groups according to blood glucose level based on diagnostic criteria for diabetes WHO 1999 (with high blood glucose group as a fasting glucose concentration (whole blood) $\geq 6.1 \mathrm{mmol} / \mathrm{L}$ and or OGTT $\geq 11.1 \mathrm{mmol} / \mathrm{L}$ and normal group was less than those value), blood pressure level based on diagnostic criteria of hypertension WHO 1999 (high blood pressure group when group systolic blood pressure $>130 \mathrm{mmHg}$ and or diastolic blood pressure $>90 \mathrm{mmHg}$ for diabetic patients with hypertension, and

\begin{tabular}{|l|l|l|l|}
\hline Region & Jexp6 & Jexp7 & Jexp8 \\
\hline Pulse sequence & gDQCosyPR & Hom2d & Tocsy \\
\hline Sampling points & 2048 & 2048 & 2048 \\
\hline Cumulative frequency & $64(\mathrm{nt}) \times 256(\mathrm{ni})$ & $64 \times 128$ & $64 \times 200$ \\
\hline Transform points & $2048 \times 2048$ & $2048 \times 2048$ & $2048 \times 2048$ \\
\hline
\end{tabular}

Table 1: Two-dimensional experiment parameters.

\begin{tabular}{|c|c|c|c|c|c|}
\hline $\begin{array}{l}\text { Serial } \\
\text { Number }\end{array}$ & Metabolite & Attribution & $\begin{array}{l}\text { Correlation } \\
\text { Coefficient } \\
r\end{array}$ & $\begin{array}{l}\text { Chemical } \\
\text { Shift/ } \\
\left(\mathrm{mg} \cdot \mathrm{L}^{-1}\right)\end{array}$ & $\begin{array}{l}\text { Metabolites change } \\
\text { of normal blood } \\
\text { glucose group and } \\
\text { high blood glucose } \\
\text { group }\end{array}$ \\
\hline 1 & Isoleucine & $\beta-\mathrm{CH}_{3}$ & 0.65 & $1.00(d)$ & $\downarrow$ \\
\hline 2 & Tyrosine & $\begin{array}{l}\mathrm{H} 3 / \mathrm{H} 5 \\
\mathrm{H} 2 / \mathrm{H} 6\end{array}$ & 0.66 & $\begin{array}{l}6.88(d) \\
7.18(d)\end{array}$ & $\downarrow$ \\
\hline 3 & a-glucose & $\begin{array}{l}\mathrm{C}-\mathrm{H} 2 \\
\text { half } \mathrm{CH} 2- \\
\mathrm{CH} 6 \\
\mathrm{H} 5 \\
\mathrm{C}-\mathrm{H} 1\end{array}$ & -0.72 & $\begin{array}{l}3.53(d d) \\
3.72(d d) \\
3.82(d d d) \\
5.23(d d)\end{array}$ & $\uparrow$ \\
\hline 4 & $\beta$-glucose & $\begin{array}{l}\mathrm{C}-\mathrm{H} 3 \\
\text { half } \mathrm{CH}_{2}- \\
\mathrm{CH}_{6} \\
\mathrm{C}-\mathrm{H}_{1}\end{array}$ & -0.76 & $\begin{array}{l}3.49(t) \\
3.90(d d) \\
4.64(d d)\end{array}$ & $\uparrow$ \\
\hline
\end{tabular}

Table 2: Blood metabolites group changes of normal blood glucose and high blood glucose cases in probable MODY families.

\begin{tabular}{|l|l|l|l|l|l|}
\hline $\begin{array}{l}\text { Serial } \\
\text { Number }\end{array}$ & Metabolite & Attribution & $\begin{array}{l}\text { Correlation } \\
\text { Coefficient } r\end{array}$ & $\begin{array}{l}\text { Metabolites } \\
\text { change of } \\
\text { Chemical } \\
\text { Shormal blood } \\
\text { pressure group } \\
\text { and high blood } \\
\text { pressure group }\end{array}$ \\
\hline 1 & Cirate & $\begin{array}{l}\text { half } \mathrm{CH}_{2} \\
\text { half } \mathrm{CH}_{2}\end{array}$ & 0.76 & $\begin{array}{l}2.52(\mathrm{~d}) \\
2.66(\mathrm{~d})\end{array}$ & $\downarrow$ \\
\hline 2 & Phaseomannite & $\begin{array}{l}\mathrm{H} 5 \\
\mathrm{H} 4 / \mathrm{H} 6\end{array}$ & 0.74 & $\begin{array}{l}3.29(\mathrm{t}) \\
3.65(\mathrm{~s})\end{array}$ & $\downarrow$ \\
\hline 3 & $\begin{array}{l}1-\text { methyl } \\
\text { histidines }\end{array}$ & $\mathrm{H} 4$ & 0.72 & $7.05(\mathrm{~s})$ & $\downarrow$ \\
\hline 4 & Tyrosine & $\mathrm{H} 2 / \mathrm{H} 6$ & 0.73 & $7.18(\mathrm{~d})$ & $\downarrow$ \\
\hline 5 & Unknown & & 0.72 & $7.32(\mathrm{~d})$ & $\downarrow$ \\
\hline
\end{tabular}

Table 3: Blood metabolites group changes of normal blood pressure and hypertension cases in probable MODY families.

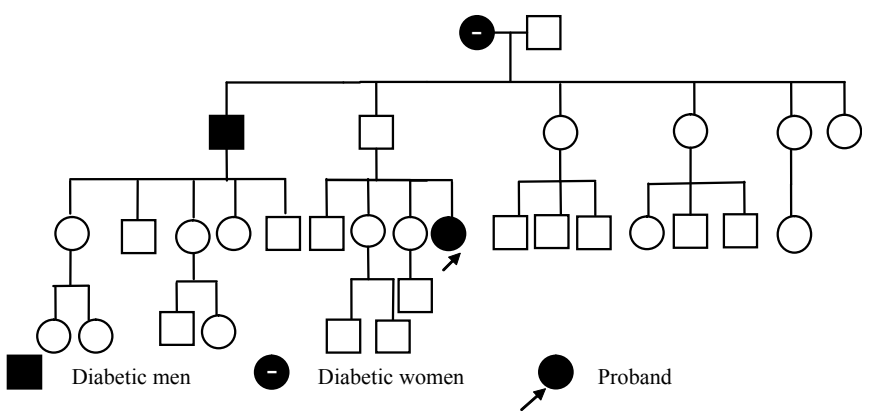

Figure 1: Probable MODY family 1 pedigree.

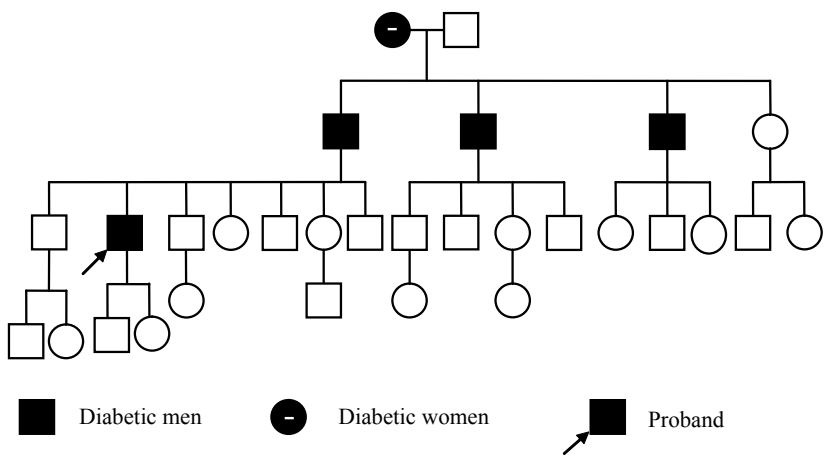

Figure 2: Probable MODY family 2 pedigrees.

otherwise normal), BMI level (high when BMI $\geq 23 \mathrm{~kg} / \mathrm{m}^{2}$ and normal when BMI was $<23 \mathrm{~kg} / \mathrm{m}^{2}$ ).

\section{${ }^{1} \mathrm{H}$ NMR spectroscopic measurements of serum metabolites}

The serum samples were prepared for NMR analysis by mixing $200 \mu \mathrm{L}$ of serum with $400 \mu \mathrm{L}$ of buffer. The serum buffer mixture was centrifuged at $10000 \mathrm{rpm}$ for 10 minutes. The clear supernatant $(550 \mu \mathrm{L})$ was then piped into a $5 \mathrm{~mm}$ NMR tube. The samples were analyzed by ${ }^{1} \mathrm{H}$ NMR spectroscopy at $599.95 \mathrm{MHz}$ using a Varian Inova600 spectrometer with the Carr-Purcell-Meiboom-Gill (CPMG) pulse sequence. For each sample, 128 scans was used into 32768 data points over a spectral width of $10000 \mathrm{~Hz}$, resulting in an acquisition time of $1.64 \mathrm{~s}$ and relaxation delay of $2 \mathrm{~s}$ at $25^{\circ} \mathrm{C}$.

\section{Data reduction}

${ }^{1} \mathrm{H}$ NMR spectra were manually phased and baseline-corrected using Topspin 2.0 software. Chemical shifts were referenced to the $\alpha$-glucose at $\delta 5.233$. Prior to data reduced into 2834 integrated regions of $0.003 \mathrm{ppm}$ corresponding to $\delta \mathrm{H}=9.0$ to $0.5 \mathrm{ppm}$, the regions $\delta \mathrm{H}=5.23$ to $4.66 \mathrm{ppm}$ were excluded from analysis because of the high variability in the intensity of the water. For each spectrum, all regions were scaled by the total integrated area as a means for normalization. Two-dimensional experiment parameters are showed in Table 1.

\section{Spectral processing and analysis}

Topspin 2.0 software (Bruker Biospin, Rheinstetten, Germany) was used for ${ }^{1} \mathrm{H}$ NMR blood pattern map to adjust baseline and phase. $\delta_{\mathrm{H}}=$ $9.0-0.5 \mathrm{ppm}$ region was selected for automatic integration, and set the integration interval as $0.003 \mathrm{ppm}$. Points system is saved in text format and imported into MS Excel tables. Since $\delta_{\mathrm{H}}=5.20-4.68 \mathrm{ppm}$ area is 
Citation: Taxitiemuer A, Yimamu Y, Mohemaiti P, Nuli R (2011) Serum Metabonomic Study of 2 Uyghur Probable MODY Families Based on ${ }^{1} \mathrm{H}$ NMR. J Diabetes Metab 2:122. doi:10.4172/2155-6156.1000122

Page 3 of 5

Blood metabolites OPLS-DA analysis result of normal blood glucose and high blood glucose groups in probable MODY families

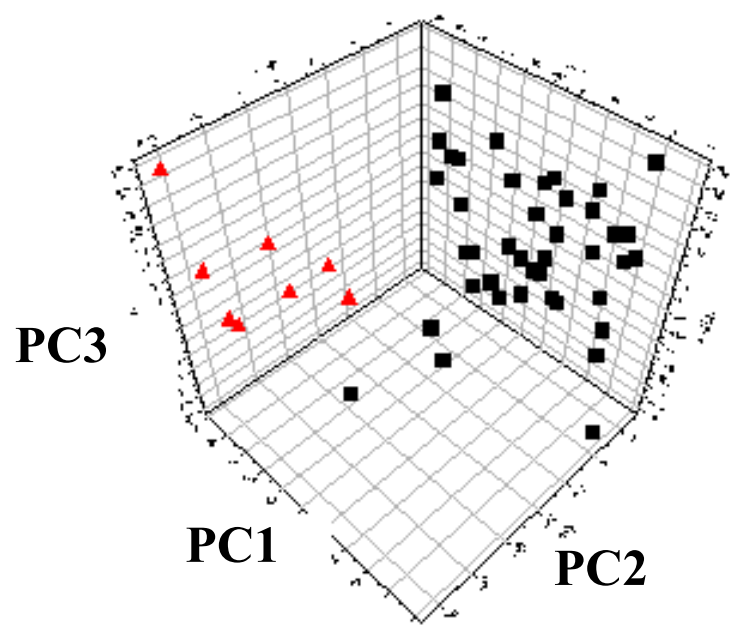

$R^{2} X=0.43, R^{2} Y=0.73, Q^{2}=0.62$

(a) as normal blood glucose cases, ( $\mathbf{A})$ as high blood glucose cases

Figure 3: ${ }^{1} \mathrm{H}$ NMR spectrum spatial distribution of normal and high blood glucose cases OPLS-DA analysis. Results show that after OPLS-DA analysis, the metabolites of two groups are significantly different.

(B)
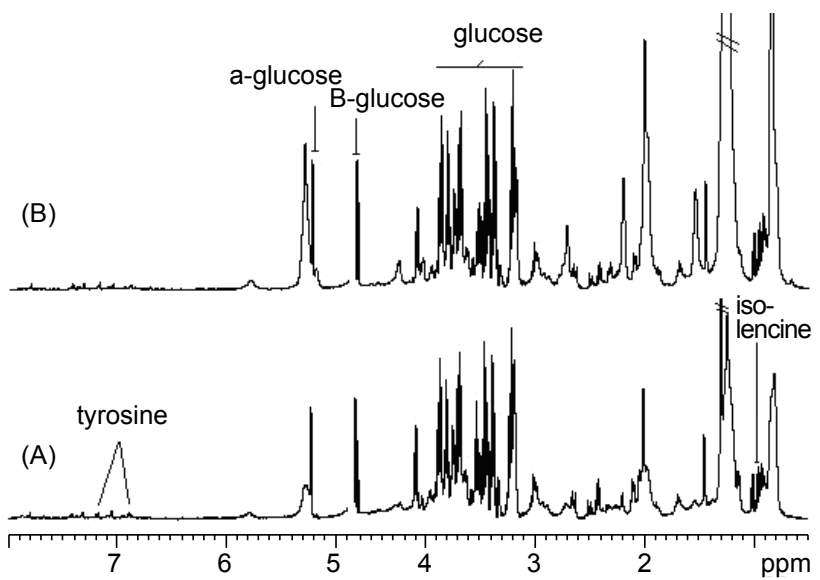

Figure 4: Normal blood glucose group (A) and high blood glucose group (B) typical serum ${ }^{1} \mathrm{H}$ NMR spectrum.

the location of water peak, therefore, the integral value in this region was excluded. After normalization of the remaining integral values, SIMCA-P +11 (Umetrics Inc., Umea, Sweden) software was used to conduct principal component analysis (PCA).

\section{Result}

Compared with normal blood glucose group, serum metabolites in high blood glucose group, isoleucine and tyrosine levels were decreased, at the same time $\alpha$-glucose, $\beta$-glucose levels were increased, and there were statistically significant differences (Figure 3, Figure 4, Table 2); Serum metabolites of hypertension group were compared with normal blood pressure group in probable MODY family members, citrate, phaseomannite, 1-methyl histidine and tyrosine levels were all decreased significantly (Figure 5, Figure 6, Table 3); No significant difference of serum metabolites was observed when comparing normal BMI group and high BMI group.

\section{Discussion}

Metabolites in biological fluids, cells, and tissues are usually in the state of dynamic balance. Cell dysfunction in organisms will definitely be reflected on organism's compositional change. All direct chemical reactions are caused by pathophysiological disorders through the combination of enzyme and nucleic acids (those two controlling

Blood metabolites OPLS-DA analysis result of normal blood pressure and hypertension cases in probable MODY families

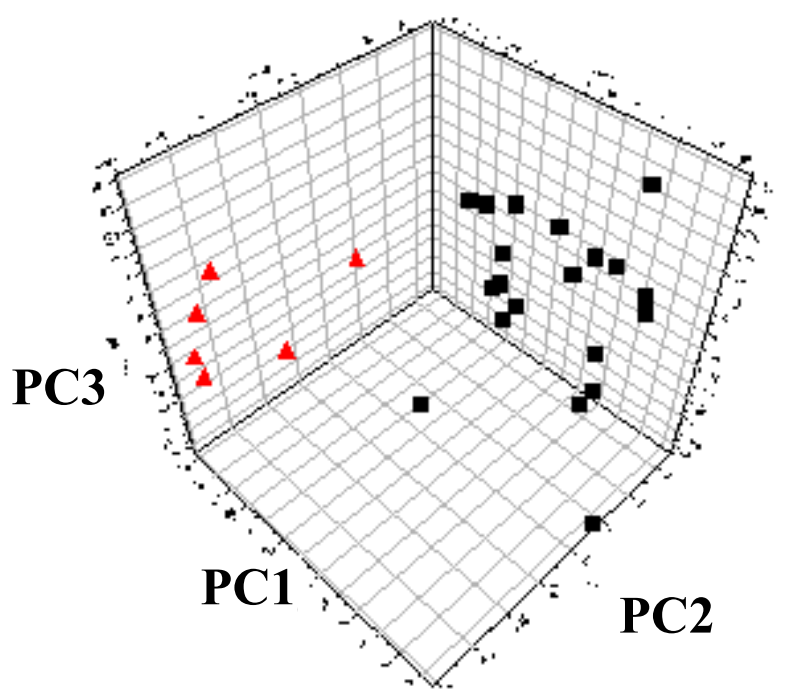

$R^{2} X=0.48, R^{2} Y=0.76, Q^{2}=0.51$

)as normal blood pressure cases()as hypertension cases

Figure 5: ${ }^{1} \mathrm{H}$ NMR spectrum spatial distribution of normal and high blood pressure cases OPLS-DA analysis. Results show that after OPLS-DA analysis, two groups of metabolites are significantly different.

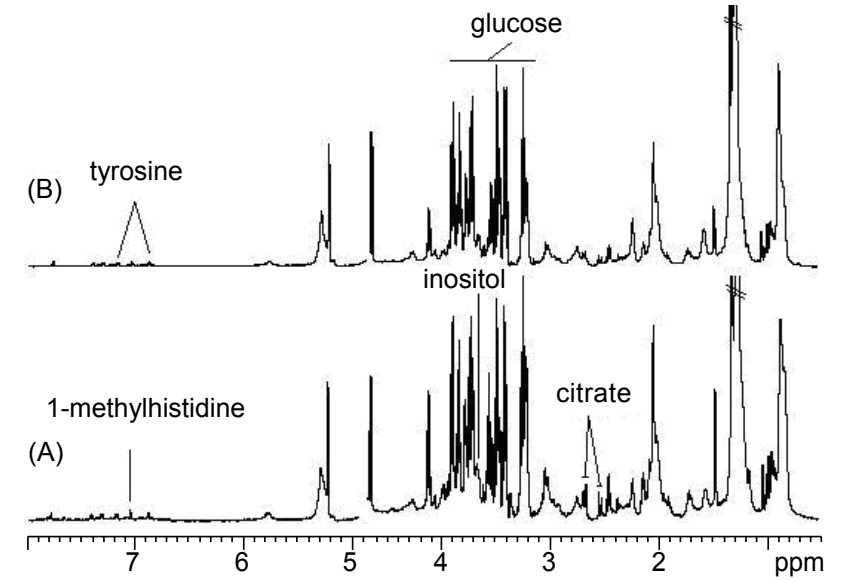

Figure 6: Normal blood pressure group $(A)$ and hypertension group $(B)$ typical serum ${ }^{1} \mathrm{H}$ NMR spectrum. 
the metabolism) [7-9]. This combination will result in disorders of endogenous biochemical substances ratio, density and metabolic flux, which will be reflected on the metabolite composition. By applying metabonomic method and studying metabolite map changes over the time, we can get complete information about the overall function in the process and its pathophysiological effect. For the disease under study, we aimed to seek early biomarkers with significant meanings and tried to bring opportunity for early disease predicting.

When high blood glucose group and normal blood glucose group were compared, isoleucine and tyrosine levels were decreased while $\alpha$-glucose and $\beta$-glucose levels were increased, and there were statistically significant differences. Branched-chain amino acids as a special kind of amino acids involved in energy supply are the important supply energy amino acids when body under the sustainable energy consumption long periods of time [10]. Isoleucine is essential amino acids for the organism. It can be obtained from the food and there is no other way. Therefore, except for metabolic disorder, another possible reason of isoleucine reduction is the lack of nutritional intake caused by dietary restrictions in patients with high blood glucose [11], but according to result of probable MODY family member's nutrition survey, Uyghur probable MODY family members did not eat less Isoleucine-rich food [12]. The diminution of serum levels of isoleucine and tyrosine in probable MODY family members with high blood glucose indicated that patients with hyperglycemia may have long-term energy loss on a sustainable basis, followed by TCA cycle metabolism disorder which reduces liver glycogen decomposition and muscle glycogen glycolysis. Not only glucose in plasma directly stimulate pancreatic $\beta$ cells to secrete insulin, but also glucose metabolites and certain amino acids promote insulin secretion, such as $\alpha$-glucose, $\beta$-glucose, and arginine $[13,14]$. Then through anti-regulation achieve glucose balance. The significant increase of $\alpha$-glucose and $\beta$-glucose in high blood glucose group indicates that: (1)The organism is insensitive or resistant to insulin secreted by $\alpha$-glucose and $\beta$-glucose thus the organism stays in high blood glucose state. (2)Probable MODY patients in sustained high energy consumption state are to promote the decomposition of glucose and glycogen metabolism.

About $30-40 \%$ of the diabetic patients have coexisting hypertension, while more than $80 \%$ of them would have abnormal glucose tolerance or obesity. Hypertension and diabetes often coexist. In a large number of epidemiological studies pointed out that hypertension was the sole predictor of type 2 diabetes. Serum metabolites of hypertension group was compared to that of normal blood pressure group in the probable MODY family, which resulted in decreased citrate, inositol, 1-methylhistidine and tyrosine levels. The decreasing level of citrate in hypertension group indicated that the TCA cycle was inhibited. This leads to increase the glucose level in blood. The obesity in patients with hypertension may because of the decrease in inositol levels, which leads to abnormal fat metabolism and increased cholesterol level. 1-methylhistidine as a goose carnosine (anserine, $\beta$-alanyl-1-methylhistidine) precursor, is abundantly present in the muscle [15]. The decrease of its quantity means glycolysis and TCA cycle metabolic disorder.

Being overweight and obese are also important factors that cause diabetes [16]. BMI is an index that reflects the degree of obesity. Many cross-sectional and longitudinal studies showed that BMI and the risk of type 2 diabetes have a positive correlation $[17,18]$. That is consistent among different genders and ethnic groups. Research has shown that: For Uyghur ethnic group members, the BMI cut-off point for risk factor in type 2 diabetes was $>23 \mathrm{Kg} / \mathrm{m}^{2}$. When the BMI is above $23 \mathrm{Kg} / \mathrm{m}^{2}$, the risk of having blood glucose abnormality is 2.05 times higher [19]. Therefore, in this study, we used BMI $>23 \mathrm{Kg} / \mathrm{m}^{2}$ as the cut point for grouping. Serum metabolites comparison of two groups showed no significant difference. Although grouping according to BMI did not distinguish the metabonomic differences between two groups, but BMI increasing and hypertension are both risk factors what closely linked with diabetes. Therefore, a proper diet, balanced nutrition, adequate exercise and regular monitoring of blood glucose and blood pressure are important to MODY family members to prevent diabetes. This is because MODY family members are more susceptible than other normal people on the diabetes.

\section{Conclusion}

(1) It can be concluded that there are the TCA cycle metabolic disorder and abnormal fat metabolism in probable MODY family members. (2)Isoleucine, citrate, inositol, 1-methylhistidine and tyrosine are the differential metabolites, They can be considered as candidate biomarkers for predicting probable MODY.

\section{Acknowledgements}

We gratefully acknowledge the support of the "National Science Foundation of China NSFC 30860114 , Key Laboratory Research Found, Xinjiang Medica University XJDX0208-2006-06.

\section{References}

1. Nicholson JK, Oflynn MP, Sadler PJ, Macleod AF, Juul SM, et al.(1984) Protonnuclear-magnetic-resonance studies of serum, plasma and urine from fasting normal and diabetic subjects. Biochem J 217: 365-375.

2. Mäkinen VP, Soininen $P$, Forsblom C, Parkkonen M, Ingman P, et al. (2006) Diagnosing diabetic nephropathy by $1 \mathrm{H}$ NMR metabonomics of serum. Mag Res Mat Phy 19: 281-296.

3. Jin ES, Burgess SC, Merritt ME, Sherry AD, Malloy CR (2005) Differing mechanisms of hepatic glucose overproduction in triodothyronine treated rats vs. Zucker diabetic fatty rats by NMR analysis of plasma glucose. Am J Physiol Endocrinol Metab 288: E654-E662.

4. Hattersley AT, Vehlo G,Froguel P (1996) Maturity-onset diabetes of the young Ball Clin Paed 4: 663-680.

5. Nyunt O, Wu JY, McGown IN, Harris M, Huynh T, et al. (2009) Investigating maturity onset diabetes of the young. Clin Biochem Rev 30: 67-74.

6. Rebiya Nuli, Patamu Mohemaiti, Yilihamujiang Yimamu, Aierken Taxitiemuer (2011) Sequencing MODY1-6 genes in Uyghur early-onset diabetes pedigree. Indian Journal of Endocrinology and Metabolism 15: 60-61.

7. Nicholson JK, Lindon JC, Holmes E (1999) "Metabonomics": understanding the metabolic responses of living systems to pathophysiological stimuli via multivariate statistical analysis of biological NMR spectroscopic data. Xenobiotica 29: 1181-1189.

8. Trethewey RN, Krotzky AJ, Willmitzer L (1999) Metabolic profiling:a rosetta stone for genomies. Curr Opin Plant Biol 2: 83-85.

9. Nicholson JK, Connelly J, Lindon JC, Holmes E (2002) Metabonomics: a platform for studying drug toxicity and gene function. Nat Rev Drug Discov 1 : 153-161.

10. JetLL, MillerRH, Nagle FJ, Lardy HA, Stratman FW (1987) Amino acid metabolism during exercise in trained rats: the potential role of carnitine in the metabolism of branched chain amino acid. Metabolism 36: 748-752.

11. Shimomura Y, Murakami T, Nakai N, Nagasaki M, Obayashi M, et al. (2000) Suppression of glycogen consumption during acute exercise by dietary branched-chain amino acids in rats. J Nutr Sci Vitaminol (Tokyo) 46: 71-77.

12. Aierken Taxitiemuer, Patamu Mohemaiti, Yilihamujiang Yimamu, et al. (2011) A survey of Uygur MODY family analysis of dietary patterns and nutrition. Disease Control and Prevention Bulletin 2: 56-59.

13. Smith PA, Sakura H, Coles B, Gummerson N, Proks P, et al. (1997) Electrogenic arginine transport mediates stimulus-secretion coupling in mouse pancreatic beta-cells. J Physiol 499: 625-635. 
Citation: Taxitiemuer A, Yimamu Y, Mohemaiti P, Nuli R (2011) Serum Metabonomic Study of 2 Uyghur Probable MODY Families Based on ${ }^{1} \mathrm{H}$ NMR. J Diabetes Metab 2:122. doi:10.4172/2155-6156.1000122

Page 5 of 5

14. Gerich JE, Charles MA, Gerold MG (1974) Characterization of the effects of arginine and glucose on glucagon and insulin release from the perfused rat pancreas. J Clin Invest 54: 833-841.

15. Safford KM, Hicok KC, Safford SD, Halvorsen YD, Wilkison WO, et al. (2002) Neurogenic differentiation of murine and human adipose-derive stromal cell. Biochem Biophys Res Commun 294: 371-379.

16. Munro HN, Femstmm TD, Wartman RJ (1975) Insulin plasma aminoacid imbalance and hepatic coma. Lancet 1: 722-724.
17. Dandona P, Aljada A, Bandyopadhyay A (2004) Inflammation: the link between insulin resistance, obesity and diabetes. Trends Immunol 25: 4-7.

18. Edward W G, Betsy L C, Yiling J C (2004) Trends in the prevalence and ratio of diagnosed to undiagnosed diabetes according to obesity levels in the U.S. Diabetes Care 27: 2806-2812.

19. Zeng Xiao-Yun, Xie Zi-Jing, Abulikemu (2006) Relationship of body mass index to glycometabolism, blood lipid and blood pressure in family members of type 2 diabetes in Xinjiang Uigur. Chinese Journal of Clinical Rehabilitation 10: 30-31. 